\title{
Research on Supervision and Guidance of Public Opinion in the New Media Era
}

\author{
Xiao-Yuan SHI \\ Zhejiang Yuexiu Foreign Languages College Shaoxing City, Zhejiang, China \\ E-mail: sxy_008@126.com
}

Keywords: Micro-blog, WeChat, Influence, Spread, Supervision and guidance.

\begin{abstract}
In the new media era, the emergence of micro-blog and WeChat gave birth to the new mode of supervision by public opinion, which in the dissemination of public opinion not only has the positive factors but also has a negative impact. Through the micro-blog and WeChat public opinion dissemination and regulatory analysis, the scale of the micro-blog and WeChat are public opinion dissemination of the soil, the network platform provides public concern about the public's quick, micro-blog and WeChat user participation is the supervision of public opinion progress, comments and forward is also the public supervision of public opinion. Think should change management concept and management mode, innovative ways to guide public opinion dissemination and strengthen the legal management of network public opinion on the micro-blog and WeChat monitoring and guidance.
\end{abstract}

\section{Introduction}

In the new media era, the emergence of micro-blog and WeChat gave birth to the new mode of supervision by public opinion, which in the dissemination of public opinion not only has the positive factors but also has a negative impact. Through the micro-blog and WeChat public opinion dissemination and regulatory analysis, the scale of the WeChat is public opinion dissemination of the soil, the network platform provides public concern about the public's quick, micro-blog and WeChat user participation is the supervision of public opinion progress, micro-blog and WeChat comments and forward is also the public supervision of public opinion. Think should change management concept and management mode, innovative ways to guide public opinion dissemination and strengthen the legal management of network public opinion on the micro-blog and WeChat monitoring and guidance. [1]

\section{The Impact of Micro-blog and WeChat on Public Opinion Dissemination}

\section{Micro-blog and WeChat Positive Impact on the Spread of Public Opinion}

Micro-blog and WeChat release of hot events so that the general public can be the first time to understand the progress of the event. In addition, some pertinent, objective and positive comments and tracking for the promotion of social positive energy, mobilization of social forces to search and rescue, rescue, restore the truth, and even some disaster events, which in a certain range to eliminate the impact of the disaster on the impact of panic, the protection of public personal and property safety, maintaining social stability, there are positive factors. At the same time, the active participation of the public is also from the other side to urge the relevant authorities to change their work attitude, improve work efficiency and play a good supervisory role.

\section{Micro-blog and WeChat Negative Impact on the Spread of Public Opinion}

Everything has its two sides, as a media platform with the media micro-blog, micro channel, the due to its own characteristics, in others, intentionally or not, for the dissemination of information also produced no small negative effects. For example, in the case of information and the dissemination of false or inappropriate comments, it is likely to distort the facts, causing panic in the public. Of course, 
there are a few people in order to attract eyeball, to attract attention to the amount of clicks or other illegal intentions, the use of micro-blog and WeChat reported false information, questioning, accusing the relevant government or government agencies. Obviously, the micro-blog, micro channel and other network information processing is not appropriate, it will have a negative impact on the community, is not conducive to the settlement of the incident, to bring unnecessary trouble. [2]These are micro-blog and WeChat in the light of the negative impact of the spread of the process.

\section{Micro-blogging and WeChat Public Opinion Dissemination and Supervision}

\section{Network has become an Important Carrier of Public Opinion}

China Internet Network Information Center released the "thirty-sixth China Internet development situation statistics report". Report shows that as of June 2015, China's Micro blog users of the scale of the Internet, Internet users use rate of $30.6 \%$. The number of micro blog users in the mobile phone number as a whole, accounting for $79.4 \%$ of the total, an increase of $10.7 \%$ compared to the end of 2014. According to 2015 micro channel user data report: 2015 micro channel is not just a mobile phone application is full of innovative features. It has become the representative of China's electronic revolution. Coverage of more than $90 \%$ of the smart phone, and called people's daily life is an integral part of the daily use of tools. Mobile phones and other electronic tools in the Internet age, has been greatly different with previous media carrier, the timeliness, convenience, and the release of obtained randomly and regulatory oversight of the micro-blog and WeChat the new media tools become the soil in the spread of a variety of public opinion.

\section{The Network Platform Provides the Public's Attention to Public Opinion}

Micro-blog and WeChat are on the rise as one of the most influential media, its rise to completely break the barrier of traditional media's professionalism, the public can only be obtained from the official opening in some of the previous information, under the new media can editions before or television broadcast before the release, the fragmentation of the event related information can be very convenient, very timely for the first time. Mobile phone as a medium of information transmission, in the context of the current manpower of a machine, so that the public access to information and delivery is very convenient, in the past, must be through traditional media such as television, newspapers and other traditional media attention, and now you can open the phone at any time through the micro-blog and WeChat public opinion attention, comments and forwarding. [3]

\section{Micro-blog and WeChat's user Participation is the Supervision of the Progress of Public Opinion}

In essence, public opinion supervision is a kind of supervision on the behavior and behavior process of public interests. The principal objects of public interest refer to government agencies and officials, as well as some enterprises and public figures involved in public interest. Therefore, the public through the micro-blog, micro channel government related functions, officials, other influential public figures and the relationship between people's health, the interests of the bad behavior of the discussion, disclosure and criticism are reflected in the way of expression of public opinion. Citizen's progress and pursuit of the incident is the right of every citizen, which is not only the law of the law, but also the rational of any individual who has the ability to conduct self-judgment. micro-blog, WeChat and other emerging Internet means so that the majority of people are able to carry out a variety of forms of expression through different forms of public opinion, but also makes the public in the event, the discourse space of public opinion more broad, the general public on the content, scope and extent of public opinion is also more extensive and far-reaching. At the same time, as the general public, the rights to participate in the supervision of public opinion also play a more extensive. No doubt, the moment of Internet tools for the spread of the spread of some public opinion in the direct mining of new issues, but also from the traditional media where grab a part of the right to set the 
agenda. Public concern and comment on a hot event, it is bound to cause the attention of traditional media, and become the object of its competing reports. [4]

\section{The Comments and forwarding of Micro-blog and WeChat Content Reflects the Public's Supervision of Public Opinion}

In recent years, many of the people's livelihood, official corruption, the impact of events, there are many ordinary people use micro-blog and WeChat and other media means to the event and the people involved in public opinion tracking and comments. By means of network for the truth surfaced, the public security organs and other government departments for the case, to speed up the progress of the process have played a good role in promoting. However, people do not seriously consider the authenticity of the release of information, its intention or intention to participate in public opinion events forward and comments, but also to the stability of the community and the functional departments of the normal work has brought a lot of unfavorable factors. In addition, some people use micro-blog and WeChat this social media for illegal activities, and even the use of public opinion to incite, for national security and social stability of hostilities. This requires the relevant functional management departments should actively attach importance to the spread of public opinion in the micro-blog and WeChat, to take effective measures to regulate, to prevent the use of criminals, so as to timely and effective propaganda and guidance.

\section{Micro-blog and WeChat Monitoring and Guidance}

\section{Change Management Concept and Management Mode}

The opening of the Internet, the freedom of public opinion in the new media era of this new feature, more direct and effective attention to public opinion events, should not be nervous, but should not feel fear. Should be aware of the characteristics, rules and effects of network communication. Polite section, timely, takes time for. Is not allowed to develop, but not rudely to let things drift, "a", "delete" and "blocking" behavior. The managers of functional management departments at all levels of government should change ideas, change the style of work, and strive to improve the management level, pay attention to the effect of network media, respect for the network public sentiment, public opinion, the authenticity of the scientific screening of public opinion, public opinion, broad channels of public. At the same time, we should stand firm, in accordance with the law and regulations in a timely and effective manner to treat, should not fear of public opinion and influence of passive network public opinion held hostage, made against the organization, violate discipline, opinions in violation the absurdity of the truth of the incident. Government departments should also be positive change management mode, realized in the new period and new media, give full play to some social organizations and the big $\mathrm{V}$ network opinion leaders, establish and improve the leadership of the Party committee, government responsibility, social coordination, public participation in the social management pattern, to strengthen the "responsibility" and the courage to bear responsibility consciousness. For micro-blog, appeared in the micro channel of public opinion events, should focus on the positive, follow up, not evade, not hide, not prevarication and fear, and actively build new major events in public opinion management mode, establish the interactive mechanism between government, industry organizations, media supervision and public relationship, and create a harmonious and healthy network environment. [5]

\section{Innovative Ways to Guide Public Opinion Dissemination}

In the past, the government's functional departments in the social management often have the characteristics of slow response, which in the rapid development of the information age; it is difficult to deal with. New media, people through the micro-blog, micro channel fragmentation of public opinion events recognition and early in the functional departments of the government officially announced the event results awareness, making the government very passive, and because of the difficult progress of events, may also lead to government because of the stagnant and the people eager 
to know something of the truth and the credibility of the decline. Therefore, in the network virtual society, the relevant government departments for this new, complex situation, the work should be innovative ways to guide the spread of public opinion. Functional departments should establish a network platform for rapid communication with the common people of the network, timely and accurate social media to inform the public about the hot issues of concern to the public, so that people enjoy the right to know. Actively will be the progress of public opinion events through open, transparent network platform to inform, to guide the network public opinion. Through the network to ask the government to collect public opinion, to play the collective wisdom of the majority of Internet users, to provide support and basis for the policy formulation.

\section{Strengthen the Legal Management of Network Public Opinion}

The new media era, people use micro-blog and WeChat and other new media in itself or groups demand expression, power supervision of government departments as well as the relation between country and society and the people's livelihood of the public management policy and actively offer advice and suggestions to, on the functions of the government sector management, event processing and the process of promoting the rule of law etc. have a positive and far-reaching impact. However, the micro-blog and WeChat and other new media in the crisis response and early warning mechanism is not perfect. Which requires government departments to set up effectively the network monitoring platform, timely understanding of the development trend of network public opinion, the first time accurately grasp the trend of network public opinion, establish corresponding early warning and response mechanism, prevent the ordinary events to the signs of the development of public opinion. The formation of network public opinion processing center, comprehensive, effective collection, analysis and processing of network public opinion information, do the analysis and prevention of sudden events, major public opinion, from a professional point of view, the network public opinion research, the different levels and age groups have to conduct psychological and behavioral research, and actively explore the new media environment, the establishment and improvement of the public appeal and voice response and guidance mechanism, timely and effective will be objective and accurate event truth, through the news media and network platform to the general public. Demands of people and questioned, should respond in a timely manner, no excuse, no escape, guide public opinion to rational and healthy direction in the development of the role.

Strengthening the construction of "rule by law" in the management of network virtual society. Relevant legal experts to establish and improve the relevant laws and regulations of the Internet, and earnestly implement the Internet information services management approach and other relevant laws and regulations, in practice, continue to explore and innovate the experience of law enforcement. According to the law to combat illegal and criminal acts of network, purify the network environment, so that the virtual network governance according to the law to the rule of law. For the use of the network to spread false information, or malicious distortion of the truth, and even encourage people to fight against the Internet and the government of the vicious incident, and cause serious consequences of the network of individuals and opinion leaders and other "big V", should be dealt with according to law. To the people of the majority of ordinary network, should actively promote the network legal education. In the interior of the media, community and enterprise carry out various forms of network of legal publicity and education, to provide reasonable and legitimate effective demands and rights protection channel to the public, at the same time, we should enhance individual network awareness of the rule of law, never be exploited by criminals and make though prohibited by the laws of the state.

\section{References}

[1] Lu Xiaowei, Micro blog on the impact of the spread of the impact of research, Shandong Normal University, 06(2013). 
[2] Zheng Bin, contemporary Chinese public demands and the interaction mechanism between the government and the government, Shanghai Normal University, 05(2011)

[3] Zhuang Hongming, freedom and responsibility -- Micro Bo celebrity social function from the perspective of interpretation , Journal of China broadcast television, 02(2014) 103-107.

[4] Wang Qingling, Research on the social function and development trend of micro blog, Central South University, 05(2013) 228-229.

[5] Bai Qingping, Research on the monitoring and guiding mechanism of university campus network public opinion in the new media era, The Guide of Science \& Education, 02(2013) 11-23. 